\title{
Recent Advances in Quartz Crystal Microbalance-Based Sensors
}

\author{
Sandeep Kumar Vashist ${ }^{1,2}$ and Priya Vashist ${ }^{1}$ \\ ${ }^{1}$ Centre for Bioanalytical Sciences, National Centre for Sensor Research, Dublin City University, Glasnevin, Dublin 9, Ireland \\ ${ }^{2}$ NUSNNI-NanoCore, T-Lab Level 11, National University of Singapore, 5A Engineering Drive 1, Singapore 117580
}

Correspondence should be addressed to Sandeep Kumar Vashist, sandeep.vashist@yahoo.com

Received 14 May 2011; Accepted 30 June 2011

Academic Editor: Michele Penza

Copyright (C) 2011 S. K. Vashist and P. Vashist. This is an open access article distributed under the Creative Commons Attribution License, which permits unrestricted use, distribution, and reproduction in any medium, provided the original work is properly cited.

Quartz crystal microbalance (QCM) has gained exceptional importance in the fields of (bio)sensors, material science, environmental monitoring, and electrochemistry based on the phenomenal development in QCM-based sensing during the last two decades. This review provides an overview of recent advances made in QCM-based sensors, which have been widely employed in a plethora of applications for the detection of chemicals, biomolecules and microorganisms.

\section{Introduction}

In 1880, Jacques and Pierre Curie discovered that when a mechanical stress is applied to certain materials such as quartz, a voltage proportional to the stress is produced [1]. In 1959, Sauerbrey demonstrated the dependence of quartz oscillation frequency on the change in surface mass [2]. He coined the term quartz crystal microbalance (QCM) in late 1950 's, and it was his work that led to the use of quartz plate resonators as sensitive microbalances for thin films. When voltage is applied to a quartz crystal causing it to oscillate at a specific frequency, the change in mass on the quartz surface is directly related to the change in frequency of the oscillating crystal, as shown by the Sauerbrey equation(1)

$$
\Delta m=-C \cdot \Delta f
$$

The change in QCM frequency determines the mass of analyte adsorbed in $\mathrm{ng} / \mathrm{cm}^{2}$. Sauerbrey equation is valid for elastic subjects such as metallic coatings, metal oxides, thin adsorbed layers, which don't dissipate any energy during oscillation. It doesn't apply to inelastic subjects such as cells, polymers, and biomolecular systems, where there is energy loss due to viscous damping during oscillation. It is invalid for soft or viscoelastic films, which do not couple completely with the oscillating crystal, thereby, causing an underestimation of mass. When the change in mass is greater than $2 \%$ of the crystal mass, the Sauerbrey equation becomes inaccurate, that is, there is no linear relationship between $\Delta f$ and $\Delta m$. QCM with dissipation (QCM-D) was developed to measure the energy dissipation in biological samples.

A QCM is a shear mode device, consisting of a thin quartz disk with coated electrodes, where the quartz crystal plate must be cut to a specific orientation with respect to the crystal axes, that is, AT or BT cut so that the acoustic wave propagates perpendicularly to the crystal surface. The resonant frequency of the quartz single crystal depends on the angles with respect to the optical axis at which the wafer was cut from the crystal. The most commonly used angle is AT cut, that is, $35^{\circ} 15^{\prime}$ from the $Z$ axis of the crystal. The temperature dependence of the resonant frequency of AT-cut crystal is essentially zero at $25^{\circ} \mathrm{C}$ as they have low temperature coefficient at room temperature, which causes minimum changes in frequency due to variation in temperature. There is decrease in the frequency of QCM due to the deposition of mass on its surface. The mass sensitivity of QCM is dependent on the thickness of the crystal, which determines its resonant frequency. The thinner is the QCM, the higher is its resonant frequency and sensitivity. However, thinner QCM is very fragile. Most commercially used QCM crystals are 0.5 inches in diameter. Optically polished crystals are recommended for liquid-phase QCM sensing as they have reduced nonspecificity. The changes in frequency and signal attenuation due to changes in viscosity of liquid makes the liquidphase QCM sensing very challenging and necessitates the use of an appropriate algorithm to separate out the effects. 


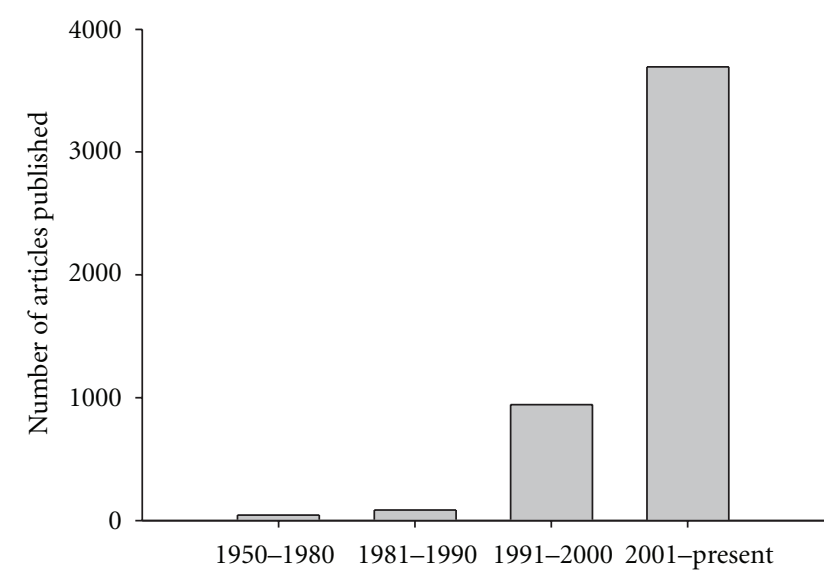

Figure 1: Number of articles published in the last few decades pertaining to QCM-based sensors (based on data taken from http:// www.sciencedirect.com/ on May 12, 2011 using "quartz crystal microbalance" and "sensors" in the advanced search option).

There has been a rapid increase in the number of publications related to QCM sensing applications during the last few decades (Figure 1). QCMs have been used for multifarious applications in various disciplines of science and technology for the detection of metals in vacuum, vapors, chemical analytes, environmental pollutants, biomolecules, disease biomarkers, cells, and pathogens (Table 1). They are also employed for deposition rate monitoring, electrochemical deposition, corrosion studies, detection in gas chromatography, and controlling thickness and composition of sputtered materials. Presently, there are several companies that are dealing with QCM-based systems (Table 2).

The sensitivity and specificity of QCM-based immunosensors is dependent on the immobilization of recognition layer. Various strategies have been employed for the immobilization of antibodies on the crystal surface. Passive adsorption of antibodies has been the most widely used method. However, it leads to random immobilization of antibodies on the surface, which may not be in functionally active orientation. The crystallizable fragment $(\mathrm{Fc})$-binding proteins such as protein A, protein G- and protein A/G are employed for oriented immobilization of antibodies on the gold-coated QCM surface such that their antigenbinding sites (Fab region) are completely free for binding antigens. Another strategy employs the initial generation of amino groups on the QCM surface by treatment with 3 -aminopropyltriethoxysilane followed by the activation of amine-functionalized surface with glutaraldehyde to generate aldehyde groups, which bind to the antibody through its amino groups. The interactions between thiols and gold are very strong and have also been exploited for antibody binding by employing self-assembled layers of thiols and sulphides. The avidin-biotin interactions have also been employed, where the avidin/streptavidin-coated QCM gold-surface is bound to the biotinylated antibody. Other approaches based on the use of polyelectrolytes, polymers, and Langmuir-Blodgett films have also been used.
Presently, several advanced analytical techniques such as fourier transform infrared (FTIR) spectrometry, gas chromatography (GC), and mass spectrometry (MS) are used for the accurate detection of various chemicals. But they are time consuming, need expensive instrumentation, and can only perform offline analysis. QCM provides one of the most promising sensor technology based on its low cost, rapid response, portability, nonhazardous label-free real-time procedure, and high sensitivity, which is ideal for the sensitive online detection of analytes and holds a great promise for the next-generation sensors.

\section{Detection of Chemicals}

2.1. Volatile Organic Compounds. The detection of volatile organic compounds (VOCs), that is, alcohols, ethers, esters, $\mathrm{NO}_{2}$, ammonia, halocarbons, chemical warfare agents, toxic gases, and so forth, is the main element of sensor technology worldwide based on the increasing threat of terrorist attacks and continuous online monitoring of military storage stations.

QCM-based multianalyte detection system, composed of six chips sensor module coated with synthetic polypeptides together with conducting polymers, was developed for the detection of acetic acid, butyric acid, ammonia, dimethyl amine, benzene, chlorobenzene, and their mixtures [3]. It demonstrated sensitive and selective detection, and discrimination via characterized odor profiles of all tested VOCs in various sensing applications. The use of principal component analysis (PCA) led to additional exploration of the sensor module properties as simple pattern recognition technique was followed.

Alcohols are volatile organic solvents being used in medicine, laboratories, industries, and many workplaces. Prolonged exposure to methanol vapour for a long time causes some diseases. QCM-based technique, based on the deposition of a thin film of polyaniline (PANI) salt, was employed for the detection of various primary aliphatic alcohols such as ethanol, methanol, 1-propanol, and 2-propanol vapours [4]. PANI was used as the sensing material due to its high environmental stability, good performance at room temperature, high electrical conductivity, good reversibility, and good reproducibility. The vapours adsorbed into the thin filmcoated QCM led to increase in its frequency shifts due to the hydrophilic nature of film, electrostatic interactions, and type of alcohol. The biosensor signal, that is, the frequency shift, had a linear correlation with the concentration of primary aliphatic alcohol vapours in the range of $2-$ $17 \mathrm{mg} / \mathrm{L}$. The sensor demonstrated good reproducibility and reversibility.

QCM-based ethanol sensor was developed which showed promising results for the online monitoring of ethanol, 0.26$0.70 \%(\mathrm{w} / \mathrm{w})$ in whole meal bread and $0.68-2.06 \%(\mathrm{w} / \mathrm{w})$ in durum-wheat bread [5]. The limit of detection and the limit of quantitation for ethanol were $1.73 \times 10^{-2} \mu \mathrm{g}$ and $3.69 \times 10^{-2} \mu \mathrm{g}$, respectively. It can be used as a quality control during bakery production for the online monitoring of ethanol concentration. 
TABLE 1: Companies dealing with QCM systems.

\begin{tabular}{ll}
\hline Companies & Websites \\
\hline Q-Sense & http://www.q-sense.com/ \\
Elchema & http://www.elchema.com/EQCN.htm \\
Inficon & http://www.inficonthinfilmdeposition.com/en/index.html \\
Masscal & http://www.masscal.com \\
ElbaTech Srl & http://www.elbatech.com/ \\
Resonant Probes & http://www.resonant-probes.de/index.htm \\
KSV & - \\
Institute of Physical Chemistry, Polish Academy of Sciences & http://www.ichf.edu.pl/offers/of_en/aparat.html \\
Tectra GmbH & http://www.tectra-gmbh.com/qmb.htm \\
Stanford Research Systems, Inc. & http://www.thinksrs.com/products/QCM200.htm\# \\
International Crystal Manufacturing Co, Inc & http://www.icmfg.com/qcm_crystals.html \\
QCM Research & http://www.qcmresearch.com/home.html \\
QCM Labs & http://www.qcmlab.com/index.htm \\
CH Instruments, Inc & http://www.chinstruments.com/Products.html \\
Lap-Tech & http://www.laptech.com/ \\
Sierra Sensors & http://www.sierrasensors.com/ \\
Eco Chemie & http://www.ecochemie.nl/?pag=13/\#EQCM
\end{tabular}

QCM-based sensor, with high sensitivity and quick response, was developed for the detection of methyl mercaptan $\left(\mathrm{CH}_{3} \mathrm{SH}\right)$ by increasing the surface area of sensing polymeric film [6]. Poly(ethylene imine) (PEI) was used as polymeric layer, whereas $\mathrm{Al}_{2} \mathrm{O}_{3}$ porous film was used to increase the surface area by coating it using sol-gel method on the QCM substrate between the QCM electrode and polymeric film. The developed sensor detected $100 \mathrm{ppb}$ of $\mathrm{CH}_{3} \mathrm{SH}$ gas and had interference with moisture, which can be corrected by using humidity sensor as feedback source.

QCM sensor array, with high sensitivity and specificity, was demonstrated for the detection of four gaseous chemical agents, that is, dimethyl methylphosphonate (DMMP), N,Ndimethylacetamide (DMA), 1,5-dichloropentane (DCP), and dichloroethane (DCE) [7]. Four appropriate coating materials were selected from 15 coating materials by applying PCA with hierarchical cluster methods to the sensor response data set collected from 15 QCM sensors for 12 analytes. These four coating materials were used to coat four QCMs in a sensor array, and PCA was adapted to classify four simulant gases.

Poly(vinylidene fluoride) (PVDF)-coated QCM sensor was developed for the detection of dimethyl methylphosphonate (DMMP) vapours, a stimulant of nerve agents [8]. The frequency shifts versus DMMP concentrations in the range of 5-60 ppm exhibit a perfect linear correlation with a correlation coefficient of above 0.997 . The sensitivity to DMMP vapour was almost identical in various humidity circumstances but higher in a lower temperature range.

Calixarene film-coated QCM sensors were used for the detection of volatile organic compounds (VOCs), that is, aromatics, chlororganics, ketones, and alcohols [9]. Calixarenes form host-guest complexes, where calixarene molecule acts as host while metal ions and different organic compounds act as guests. The sensitivity and selectivity of calixarenes vary depending on the numbers of aryl fragments and the binding of different functional groups to upper and lower rims. The numbers of aryl fragments affect the size and shape of the cavity. Phosphorous-containing calixarenes showed maximal sensitivity, which makes them attractive for sensor applications. Further efforts are devoted to enhance the sensitivity and selectivity of sensor coatings for the detection of specific analytes.

QCM-based VOC vapour sensor was developed for the detection of toluene and $p$-xylene [10]. Toluene and $p$-xylene molecular imprinted polymers (MIPs), composed of methyl methacrylate (MMA) as a monomer and divinylbenzene (DVB) as a cross-linking agent, were prepared in the presence of toluene and $p$-xylene using conventional cross-linking polymerization. These solvent molecules produced their own recognition sites inside the polymer matrix during the polymerization process. MIP powders were blended with PMMA and coated on QCM for the development of VOC sensor. The toluene and $p$-xylene imprinted polymers showed their specific tendencies to reversibly bind toluene and $p$-xylene preferably based on the molecular imprinting effect although the response time was slow due to the presence of matrix polymer around the MIP particles. Thus, there is tremendous potential in this technique for the development of QCM-based sensors for VOCs. However, further improvements are still desired for increasing the selectivity and response time.

Miniaturized QCM arrays, with up to 36 QCM on a single AT-cut quartz blank, were developed and used for the detection of toluene in water by coating the QCM sensor array with different layers such as polystyrene, amylcalix[8]arene, and $\beta$-cyclodextrin [11]. The sensitivity of the polystyrene coating to the toluene in water was directly proportional to the resonant frequency. However, the higher is the sensitivity, the higher is the noise due to lower quality 
TABLE 2: QCM-based sensing applications.

\begin{tabular}{|c|c|c|}
\hline Analytes & Detection limits & References \\
\hline $\begin{array}{l}\text { Acetic acid, butyric acid, ammonia, dimethyl amine, benzene, and } \\
\text { chlorobenzene }\end{array}$ & N.M.* & {$[3]$} \\
\hline $\begin{array}{l}\text { Primary aliphatic alcohols such as ethanol, methanol, 1-propanol, } \\
\text { and 2-propanol }\end{array}$ & $2-17 \mathrm{mg} / \mathrm{L}$ & {$[4]$} \\
\hline Ethanol & $1.73 \times 10^{-2} \mu \mathrm{g}$ & {$[5]$} \\
\hline $\mathrm{CH}_{3} \mathrm{SH}$ & $100 \mathrm{ppb}$ & {$[6]$} \\
\hline DMMP, DMA, DCP, DCE & N.M.* & [7] \\
\hline DMMP & $5-60 \mathrm{ppm}$ & {$[8]$} \\
\hline VOCs such as aromatics, chlororganics, ketones, and alcohols & N.M.* & {$[9]$} \\
\hline Toluene and $p$-xylene & N.M.* & {$[10]$} \\
\hline Toluene & N.M.* & {$[11]$} \\
\hline Xylene isomers & $0-200 \mathrm{ppm}$ & {$[12]$} \\
\hline Alcohols, esters, acids, and aldehydes & N.M.* & {$[13]$} \\
\hline Bisphenol-A & $0.01 \mathrm{ng} / \mathrm{mL}$ & {$[14]$} \\
\hline TCDD & $0.1-100 \mathrm{ng} / \mathrm{mL}$ & {$[15]$} \\
\hline DDVP & $6.5-32.5 \mathrm{ppm}$ & {$[16]$} \\
\hline 1-NAP and 2-NAP & $\begin{array}{l}8.362 \times 10^{-7} \mathrm{~mol} / \mathrm{L} \text { for } 1-\mathrm{NAP} \\
2.146 \times 10^{-7} \mathrm{~mol} / \mathrm{L} \text { for } 2-\mathrm{NAP}\end{array}$ & {$[17]$} \\
\hline $\mathrm{HCl}$ & ppt level with sensitivity of $0.1 \mathrm{ppm} / \mathrm{Hz}$ & {$[18]$} \\
\hline \multirow{3}{*}{ Methane } & $250 \mathrm{ppb} / \mathrm{Hz}$ sensitivity & {$[19]$} \\
\hline & $0.05 \%(\mathrm{v} / \mathrm{v})$ & {$[20]$} \\
\hline & N.M.* & {$[21]$} \\
\hline NO & $25 \mathrm{ppb} / \mathrm{Hz}$ sensitivity & {$[22]$} \\
\hline $\mathrm{NO}_{2}$ & $\begin{array}{l}\text { Sub-ppm level with sensitivity of } 1200 \mathrm{~Hz} / \mathrm{h} \text { for } \\
\qquad 50 \mathrm{ppm} \mathrm{NO} 2\end{array}$ & {$[23]$} \\
\hline \multirow[t]{2}{*}{ Chloroform } & N.M.* & {$[24]$} \\
\hline & N.M.* & {$[25]$} \\
\hline \multirow[t]{2}{*}{$\mathrm{NH}_{3}$} & N.M. ${ }^{*}$ & {$[26]$} \\
\hline & $0.3-15 \mathrm{ppm}$ with LOD of $0.1 \mathrm{ppm}$ & [27] \\
\hline $\mathrm{HCHO}$ & $3 \mathrm{ppm}$ & [28] \\
\hline L-mandelic acid & N.M.* & [29] \\
\hline Orange and melon flavors & N.M.* & {$[30]$} \\
\hline Ethanol, acetone, and trichloroethylene gas mixtures & N.M. ${ }^{*}$ & {$[31]$} \\
\hline Humidity & Sensitivity of $12.32 \mathrm{~Hz} / \mathrm{RH} \%$ & {$[32]$} \\
\hline Ag ions & N.M.* ${ }^{*}$ & {$[33]$} \\
\hline Olive oils & N.M.* & {$[34]$} \\
\hline Nanoparticles (Si and Ag nanopowder, rhodamine B, and ferrocene) & Linear up to $1300 \mu \mathrm{g} / \mathrm{mL}$ & {$[35]$} \\
\hline Glucose & $0.01-7.5 \mathrm{mM}$ with LOD of $5 \mu \mathrm{M}$ & {$[36]$} \\
\hline Albumin & $60-150 \mathrm{ppm}$ & [37] \\
\hline PSA and PSA-ACT & $\begin{array}{l}\text { Linear dynamic range up to } 150 \mathrm{ng} / \mathrm{mL} \text { with } \\
\text { LOD of } 0.29 \mathrm{ng} / \mathrm{mL}\end{array}$ & {$[38]$} \\
\hline CRP & N.M.* & {$[39]$} \\
\hline EPGF & $0.01-10 \mu \mathrm{g} / \mathrm{mL}$ & {$[40]$} \\
\hline L tryptophan & LOD $8.8 \mu \mathrm{M}$ & {$[41]$} \\
\hline Glycoproteins & $50 \mu \mathrm{g} / \mathrm{mL}-1 \mathrm{mg} / \mathrm{mL}$ & {$[42]$} \\
\hline Folic acid & $\begin{array}{l}\text { Linear range of } 0-100 \mu \mathrm{M} \text { with LOD of } \\
\qquad 15.4 \mu \mathrm{M}\end{array}$ & {$[43]$} \\
\hline Vibrio harveyi & $10^{3}-10^{7} \mathrm{CFU} / \mathrm{mL}$ & {$[44]$} \\
\hline Campylobacter jejuni & N.M.* & {$[45]$} \\
\hline D. desulotomaculum & $1.8 \times 10^{4}-1.8 \times 10^{7} \mathrm{cfu} / \mathrm{mL}$ & {$[46]$} \\
\hline
\end{tabular}

* N.M.: Not mentioned. 
factor. Therefore, the toluene detection has to be done at the optimum resonant frequency, which depends on the stability of temperature and pressure control.

QCM sensor array having four QCMs was employed for the detection of xylene isomers in the range of 0-200 ppm with an accuracy of about 1\% [12]. The sensor was specific for $m$-xylene and $p$-xylene without any cross-sensitivity with the residual water, thereby enabling analyte detection in the presence of variable ambient humidity. The supramolecular host molecules were used as coating materials for QCM resonators and combined with multivariate data analysis for the detection of xylene isomers. The low-cost sensor array is highly stable chemically and physically, and thus appropriate for specific continuous online monitoring of gaseous analytes under very harsh conditions.

PEGylated lipopolymer containing disulphide as supports for the lipid and lipopolymer odor sensing materials was chemisorbed on QCMs [13]. The sensors with supports were found to be more sensitive than the nonsupported counterparts due to higher fluidity of supported films. This was evident by the evaluation of the overall sensing properties by PCA. The sensors were able to discriminate among the ten odorants tested, that is, alcohols (1-butanol, 1-hexanol, trans-2-hexenol), esters (butyl acetate, hexyl acetate, trans-2hexenyl acetate), acids (isobutyric, hexanoic), and aldehydes (butanal, trans-2-hexenal).

2.2. Bisphenol-A, Dioxin Compounds, DDVP, and Naphthol. Bisphenol-A (BPA)/[4,4'-(1-methylethylidene) bisphenol] was detected using anti-BPA monoclonal-antibody immobilised on QCM [14]. After the specific detection of BPA, the signal was enhanced by adding a secondary antibody tagged with a conjugated microsphere. Anti-BPA antibody was conjugated to 2-methacryloyloxyethyl phosphorylcholine (MPC) polymeric nanoparticles, and polystyrene nanoparticles of the same size, that is, $202 \mathrm{~nm}$. MPC polymeric nanoparticles tagged anti-BPA had greater signal enhancement with highly stable signal as MPC polymeric nanoparticles had excellent colloidal stability resulting from strongly solvation with water molecules that resisted the coagulation of these nanoparticles. The signal enhancement step decreased the limit of detection from $0.1 \mathrm{ng} / \mathrm{mL}$ to $0.01 \mathrm{ng} / \mathrm{mL}$, thereby, demonstrating the increase in analytical sensitivity of assays dealing with small analytes.

In another approach [47], MIP was bound to the selfassembled monolayer (SAM)-coated QCM Au electrode for the detection of BPA. SAM, composed of 2-aminoethanethiol and 11-mercaptoundecanoic acid, had ion-pair interactions with the functional monomers in MIP to form proper adhesions. MIP contained specific cavities by self-organized structure of functional monomers around a template. The sensor can detect BPA selectively in the liquid phase with a sensitivity of $100 \mathrm{ppb}$. It was observed that polymerization solution without solvent had better sensor performance, MIP-QCM sensor with SAM was better in terms of stability than that without SAM, greater weight of membrane improved the sensitivity of the sensor, and the optimized material type and its composition can lead to improved sensor.
A portable QCM-based dioxin sensor was developed to detect the concentration of 2,3,7,8-tetrachlorodibenzop-dioxin (TCDD) [48], which is the most toxic molecule among dioxin-like compounds and is considered as a reference for this class of compounds. QCM surface was chemically treated with cysteamine and glutaraldehyde, and then bound to anti-TCDD monoclonal antibody. The unreacted aldehyde groups were blocked with glycine. MPC polymer was used as a stabilizer to reduce the nonspecific binding of the antigen solution and to stabilize the immunologic activity of antibody-functionalised QCM. The biosensor was effective for the analysis of dioxins in fly ash samples $[15,48]$. There was a linear response to $0.1-100 \mathrm{ng} / \mathrm{mL}$ TCDD with linear correlation of 0.99 , which was similar to ELISA.

QCM sensor, with enhanced sensitivity, was developed for organophosphorous pesticide o,o-dimethyl-o-2,2-dichlorovinyl phosphate (DDVP) by modifying the geometry and size of the electrodes and depositing conductive polymers on the surface of the electrode [16]. The change in resonant frequency, which is a measure of the electrical loading, corresponds to the change in electrostatic capacitance. The sensor's sensitivity was directly proportional to the conductivity of polymer coating. The capacitance was in the range of $0.198-0.187 \mathrm{pF}$ for the poly(3,4-ethylenedioxythiophene) (PEDOT)-conductive polymer film. The relationship between PEDOT-coated sensor response and DDVP concentration was linear in the range of $6.5-32.5 \mathrm{ppm}$. PEDOT film-coated sensor was used to measure three DDVP samples with the relative standard deviation of less than $5 \%$.

The high sensitivity of QCM, with $\beta$-cyclodextrin $(\beta$ $\mathrm{CD}) / \mathrm{TiO}_{2}$ composite film, was coupled with excellent predictive ability of chemometrics, for the simultaneous determination of 1-naphthol (1-NAP) and 2-naphthol (2NAP) in human urine samples [17]. $\beta$-CD was immobilized onto the QCM surface using nanocrystalline $\mathrm{TiO}_{2}$ films as substrates. The correlation coefficients for 1-NAP and 2-NAP were 0.993 and 0.990 , respectively, whereas the LODs were $8.362 \times 10^{-7} \mathrm{~mol} \mathrm{~L}^{-1}$ and $2.146 \times 10^{-7} \mathrm{~mol} \mathrm{~L}^{-1}$, respectively.

2.3. Gaseous Analytes. QCM-based $\mathrm{HCl}$ gas sensor was developed using morpholine-functional poly(styrene-cochloromethylstyrene) copolymer coatings, which was good for one-shot detection of $\mathrm{HCl}$ gas as it bind irreversibly to the sensor coating [18]. The sensitivity of the sensor was dependent on the chemical structure and the composition of copolymer. It detected ppt level of $\mathrm{HCl}$ with sensitivity of $0.1 \mathrm{ppm} / \mathrm{Hz}$ for $10 \mathrm{~min}$ sensor operation. The largest sensitivity was obtained when the sensor film coating copolymer was composed of $40 \mathrm{~mol} \%$ chloromethylstyrene cross-linked with $5 \mathrm{~mol} \%$ divinylbenzene, and the film thickness was greater than $2 \mu \mathrm{m}$. However, substantial interference was produced by changes in humidity and $\mathrm{NO}_{2}$, which can bias the use in some industrial applications such as the analysis of combustion gases. The device was, however, not affected by other gases such as $\mathrm{O}_{2}, \mathrm{CO}_{2}$, and $\mathrm{SO}_{2}$.

In another approach, QCM-based sensor was developed for the detection of $\mathrm{HCl}$ gas in air-using coatings of three different kinds of poly(acrylamide) derivates [19]. The sensitivity, response time, and reversibility of the sensor were 
dependent on the structure of the amide group. The polymer poly(N,N-dimethylacrylamide) (PDMAA) was the best for $\mathrm{HCl}$ sensing with a sensitivity of about $250 \mathrm{ppb} / \mathrm{Hz}$. However, the sensor still had considerably high irreversible response towards $\mathrm{NO}_{2}$ gas and high interference to changes in test gas humidity, which limit its practical applications. The future efforts by the group are devoted to prepare a reliable and practical $\mathrm{HCl}$ gas sensor.

Supramolecular cryptophane-A-based QCM sensor was used for the selective and rapid detection of methane with high recovery at room temperature and a detection limit of $0.05 \%(\mathrm{v} / \mathrm{v})[20]$. The supramolecular cryptophane-A was synthesized from vanillyl alcohol by double trimerisation method and deposited on the QCM surface by electrospraying.

PANI/PdO composite, synthesized by in situ chemical oxidative polymerization of aniline with $\mathrm{PdO}$ nanoparticles, was deposited on QCM through layer-by-layer self-assembly method and employed for detecting methane [21]. The sensor response decreased with the increase in relative humidity and was better at room temperature than at $50^{\circ} \mathrm{C}$.

QCM sensor for the detection of nitric oxide (NO) in gaseous state was developed by immobilizing cobalt phthalocyanine $(\mathrm{CoPc})$ in a mesoporous silica matrix deposited on QCM [22]. CoPc/mesoporous silica hybrids were prepared by thermal calcinations process and characterised by fourier transform infrared spectroscopy (FTIR) and scanning electron microscopy (SEM). CoPc/mesoporous silica-coated QCM was compared with nonmodified QCM and CoPc-modified QCM for sensitivity enhancement. $\mathrm{CoPc} /$ mesoporous silica-coated QCM had highest sensitivity of up to $25 \mathrm{ppb} / \mathrm{Hz}$ with minimum cross-sensitivity to carbon monoxide (CO).

Morpholine-functional cross-linked copolymer coatings were developed for QCM for the detection of sub-ppm level of nitrogen dioxide in air [23]. The cross-linked poly(styrene-co-chloromethyl styrene) copolymer reacted with morpholine to generate the morpholine-functional cross-linked copolymer. The developed QCM-based sensor is suitable for one-shot detection of $\mathrm{NO}_{2}$ concentrations in air. The largest sensitivity obtained was $1200 \mathrm{~Hz} / \mathrm{h}$ for $50 \mathrm{ppm}$ of $\mathrm{NO}_{2}$.

The paracyclophanes B44TOS and CP44 were coated on the surface of QCM, and chloroform vapors were detected by the formation of host-guest complexes between chloroform and paracyclophanes [24]. The mass-sensitive detection was further confirmed by FTIR spectroscopy and Brunauer, Emmett, and Teller theory (BET) adsorption analysis.

Electrospun nanoporous membrane-coated QCM sensor was developed for the detection of ammonia [25]. The electrospun nanofibers, composed of cross-linkable poly(acrylic acid) (PAA) and poly(vinyl alcohol) (PVA), and having diameter of 100-1400 nm, were deposited on QCM by electrospinning. The average diameter and rigidity of nanofibers increased with the increase in viscosity and conductivity of the homogeneous blend solution of PAA and PVA due to the increased PAA content. The sensitivity of nanofibrous membrane-coated QCM was much higher than that of continuous films-coated QCM. The sensing properties were

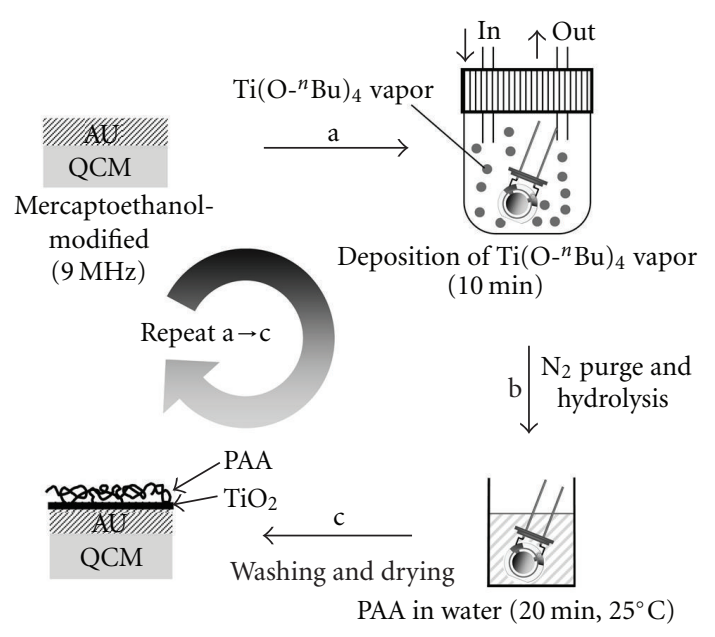

(a)

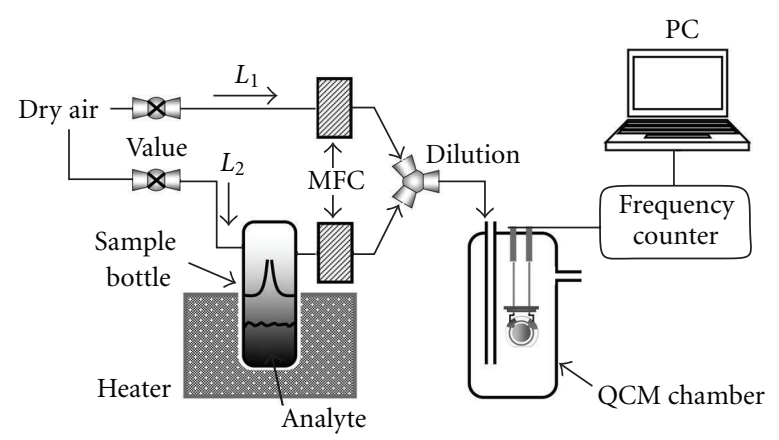

(b)

FIGURE 2: (a) Schematic illustration of the film preparation by the gas phase surface sol-gel process. (b) Schematic diagram of the QCM measurement setup (Lee et al., 2010) [27]. (Reprinted with permission from ACS Publications.)

affected by the content of PAA in nanofibrous membranes and relative humidity.

A highly selective, reproducible, and stable sensor, based on $\mathrm{ZnO}$ nanorods-coated QCM, was developed for detecting $\mathrm{NH}_{3}$ at room temperature [26]. Vertically-aligned $\mathrm{ZnO}$ nanorods, with diameter of $100 \mathrm{~nm}$ and height of $3 \mu \mathrm{m}$, were synthesized directly on the Au electrode of QCM by wet chemistry at $90^{\circ} \mathrm{C}$. The sensor showed good selectivity to $\mathrm{NH}_{3}$ over liquefied petroleum gas, $\mathrm{N}_{2} \mathrm{O}, \mathrm{CO}, \mathrm{NO}_{2}$, and $\mathrm{CO}_{2}$.

QCM sensor was developed for the sensitive detection of amine odors by employing an ultrathin film formed by the alternate adsorption of $\mathrm{TiO}_{2}$ and polyacrylic acid (PAA) [27] (Figure 2). The developed sensor was very fast in response, stable in a relative humidity range of $30-70 \%$, and had a linear range of $0.3-15 \mathrm{ppm}$ with LOD of $0.1 \mathrm{ppm}$ for the detection of ammonia, which binds to the free carboxylic groups of PAA by acid-base interactions. The $\mathrm{TiO}_{2} / \mathrm{PAA}_{400}$ ultrathin film was capable of condensing $15 \mathrm{ppm}$ ambient ammonia concentration to $\sim 20,000 \mathrm{ppm}$. The sensitivity to n-butylamine and ammonia was found to be higher in comparison to pyridine due to differences in their molecular weight and basicity. 


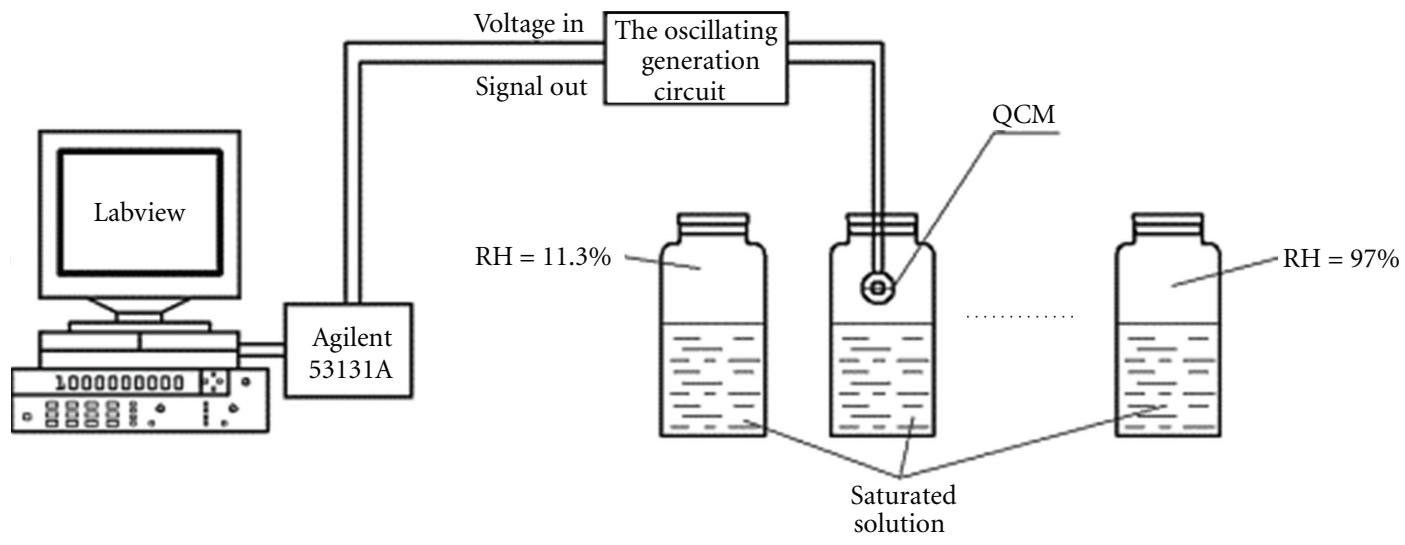

Figure 3: QCM setup for humidity testing (Zhu et al., 2010) [32]. Reprinted with permission from Elsevier B.V.

Electrospun nanoporous polystyrene fibres, with high surface area-to-volume ratio $\left(\sim 47.25 \mathrm{~m}^{2} / \mathrm{g}\right)$, were deposited on polyethyleneimine (PEI)-functionalized QCM and employed for highly sensitive and rapid detection of $\mathrm{HCHO}$ with a LOD of $3 \mathrm{ppm}$ [28]. The PS fibers, electrospun from higher concentration of PS solution (13wt\%), had larger pore size and greater surface area than PS fibers electrospun from less concentration of PS. Therefore, the sensor response of PEI-PS $(13 \mathrm{wt} \%)$ for the detection of $140 \mathrm{ppm} \mathrm{HCHO}$ was four fold greater than that of PEI-PS ( $7 \mathrm{wt} \%)$.

2.4. Chiral Recognition, Odor Approximation, and Composition Analysis. An L-phenylalanine-coated QCM sensor and vapour-diffused molecular assembly (VDMA) reaction technique were employed for the highly selective chiral recognition of L-mandelic acid (L-MA) with the chiral discrimination factor, that is, L-MA/D-MA of about 8 [29]. The developed QCM-based procedure was simple and better than the diastereomeric crystallization technique, where the screening of resolving agents is challenging. The QCMchiral recognition results were in agreement with the results obtained by diastereomeric crystallization separation of racemate MA using L-phenylalanine as resolving agent. The selective detection of L-MA was further confirmed by contact angle measurements. Similar strategy can be adopted for the screening of suitable resolving agents for chiral enantiomers in chiral resolution.

Odor approximation is a challenging task as odors are mixtures of hundreds of different kinds of molecules. However, there are some character impact odorants in the case of fruit flavours, which are helpful for performing an approximation of fruit flavours. An array of QCM odor sensors coated with different materials, such as lipids and stationary phase material of gas chromatography, was employed for odor approximation of orange and melon flavours [30]. The lipids used were divaleroyl phosphatidyl choline (DVPC), cardiolipin (CL), and cerebrosides (CSs), whereas the stationary phase material of gas chromatography employed was apiezon-L (Ap-L). Initially, the steadystate sensor responses to single flavour components were measured. Thereafter, the important odor components were estimated by computational two-level quantization method. The experimental approximation was performed using the steady-state sensor responses and PCA. The orange flavour can be approximated using an array of four sensors, where the odor approximation can be done using three odor components, that is, linalool, decanal, and citral. However, in the case of melon flavour as the number of odor components increased, a DVPC-coated QCM was further included as the fifth component of the sensor array. Human sensory test was performed to evaluate the similarities between approximated odors and original ones, which were observed to be high in the case of orange flavour. But it is possible to approximate the melon flavour much better by increasing the number of odor components in approximate flavour.

An array of eight phthalocyanine-coated QCM sensors and an artificial neural network were used for finding the composition of gas mixtures [31]. The preprocessing of digital data collected from the sensor responses was done by a sliding window algorithm followed by a threelayer artificial neural network, which was used to determine the composition of the gas mixtures. The developed sensor system was tested with various gas mixtures such as ethanol-acetone, ethanol-trichloroethylene, and acetonetrichloroethylene with a success rate of greater than $84 \%$ and overall prediction error of $10.6 \%$. The developed procedure is only applicable to the gaseous mixtures belonging to a certain specified categories but can be readily expanded to other gas species.

2.5. Other Applications. Mesoporous silicate SBA-15 with monodisperse hexagonal lamelliform was prepared and coated on QCM to form low-cost, highly stable, reproducible, and sensitive humidity sensor [32] (Figure 3). The sensitivity of the developed sensor was directly proportional to the film's thickness. The best linearity was obtained with a SBA-15 film of $20 \mathrm{~nm}$ thickness having the sensitivity of $12.32 \mathrm{~Hz} / \mathrm{RH} \%$.

The sensing of silver ions in aqueous media was demonstrated by the deposition of nanotubular PANI film on QCM, 
where the increased mass due to the reduction of silver ions with PANI caused the decrease in QCM frequency [33]. The procedure can be used for monitoring industrial waste waters and searching new resources of silver.

Eight QCM sensor arrays, with five gas chromatographic stationary phases (OV-17, OV-275, PEG, Span 80, and Vaseline) as sensing films and PCA method, were used for differentiating virgin and extravirgin olive oils from lampante ones [34]. The method is cheap, easy to use, and doesn't employ any solvents or pretreatment of the sample.

QCM was employed to accurately determine the concentration of nanoparticles in a colloidal suspension using a simple procedure based on the drop casting of nanoparticle suspension in a volatile solvent, which leaves a dry nanoparticle residue after solvent evaporation on the QCM surface [35] (Figure 4). There was a linear response for nanoparticle concentrations up to $1300 \mu \mathrm{g} / \mathrm{mL}$ in the calibration experiments done with serial dilutions of $\mathrm{Si}$ and $\mathrm{Ag}$ nanopowder in methanol, rhodamine B in methanol, and ferrocene in cyclohexane. The developed procedure determined the concentrations of size-selected, octyl-terminated Si nanocrystal samples with median diameters in the range of 1.1-14.8 $\mathrm{nm}$.

\section{Detection of Biomolecules}

A displacement assay was developed for the nonenzymatic glucose detection, where glucose molecules displace concanavalin A (conA) molecules bound to the dextranfunctionalized graphene-coated QCM, thereby, leading to a change in frequency [36] (Figure 5). Phenoxy-derived dextran (DexP) molecules were initially bound to graphenecoated QCM surface by $\Pi$-П stacking, which was followed by the binding of conA molecules based on their specific interactions with DexP. The dynamic range of the glucose sensing assay was $0.01-7.5 \mathrm{mM}$ with a LOD of $5 \mu \mathrm{M}$.

MIP-coated QCM sensor was developed for the determination of albumin concentration [37]. Albumin was imprinted with 3-dimethylaminopropyl methacrylamideacrylate. The albumin MIP was then coated on QCM Au electrode. In the tetraethylene glycol dimethacrylate-crosslinked polymer system, the adsorption capacity of different Au electrodes was in the decreasing order of $\mathrm{Au}-\mathrm{OH}>\mathrm{Au}-\mathrm{COOH}>$ $\mathrm{Au}-\mathrm{NH}_{2}>\mathrm{Au}$, whereas the time taken to achieve a steadystate frequency was in the decreasing order of Au- $\mathrm{NH}_{2}<\mathrm{Au}-$ $\mathrm{OH}<\mathrm{Au}-\mathrm{COOH}<\mathrm{Au}$. However, in the trimethylolpropane trimethacrylate cross-linking system, the adsorption capacity of different electrodes was in the decreasing order of $\mathrm{Au}>$ $\mathrm{Au}-\mathrm{NH}_{2}>\mathrm{Au}-\mathrm{OH}>\mathrm{Au}-\mathrm{COOH}$. The developed albumin MIP-QCM sensor had higher response to albumin than non-MIP-QCM sensor. The adsorption ratios of cytochrome c: lysozyme: albumin : myoglobin were $160: 1: 1942: 30$ and $13: 1: 249: 86$ for albumin MIP-QCM and non-MIP-QCM, respectively. The developed sensor had a linear range from 60 to $150 \mathrm{ppm}$ for albumin. The clinical application of the developed sensor was tested by determining the albumin concentration in human serum. The values obtained by MIP-QCM and clinical assay were $4.80 \mathrm{~g} / \mathrm{dL}$ and $4.60 \mathrm{~g} / \mathrm{dL}$, respectively, which showed good correlation and, thereby, demonstrate the potential of the developed sensor for clinical applications.

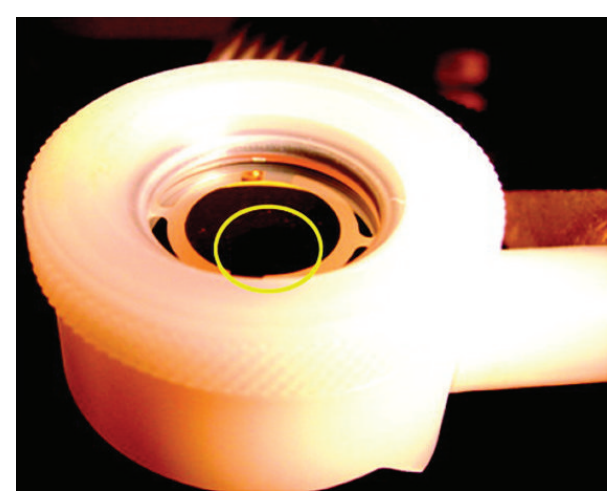

(a)

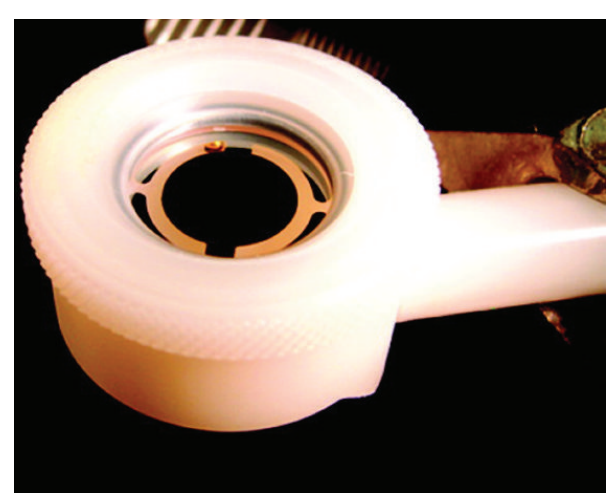

(b)

FIGURE 4: Quartz crystal images: (a) following the application of a nanocrystal colloidal suspension, circle indicates residual solvent; (b) following complete solvent evaporation (Reipa et al., 2010) [35]. (Reprinted with permission from ACS Publications.).

Antibody-bound QCM with Au nanoparticle-based signal amplification was employed for detecting prostate-specific antigen (PSA) and PSA-alpha 1-antichymotrypsin (ACT) complex in human serum (75\%) [38]. The LOD of PSA and PSA-ACT complex in $75 \%$ human serum was $0.29 \mathrm{ng} / \mathrm{mL}$ with the linear dynamic range of up to $150 \mathrm{ng} / \mathrm{mL}$. The interfering signal in human serum was reduced by $98 \%$, when PBS buffer, having $200 \mu \mathrm{g} / \mathrm{mL}$ BSA, $0.5 \mathrm{M} \mathrm{NaCl}, 500 \mu \mathrm{g} / \mathrm{mL}$ dextran, and $0.5 \%$ Tween 20 , was used.

An indirect competitive-QCM immunosensors were developed, where $2 \mathrm{mg} / \mathrm{mL}$ of C-reactive protein (CRP) was bound to the surface, and the change in frequency was monitored after providing $200 \mu \mathrm{L}$ of biotinylated antirat CRP antibody mixed with streptavidin-coated gold nanoparticle [39] (Figure 6). There was 53\% signal enhancement by this procedure in comparison to the conventional procedure using unmodified antibody.

QCM immunosensor was developed for the detection of epidermal growth factor receptor (EGFR) with a linear range of $0.01-10 \mu \mathrm{g} / \mathrm{mL}$ [40]. Anti-EGFR antibody was immobilized on the gold surface by thiosalicylic acid-based selfassembled monolayer (SAM) followed by activation with 1-[3-(dimethylamino)propyl]-3-ethylcarbodiimide hydrochloride (EDC) and $N$-hydroxysuccinimide (NHS). Two 


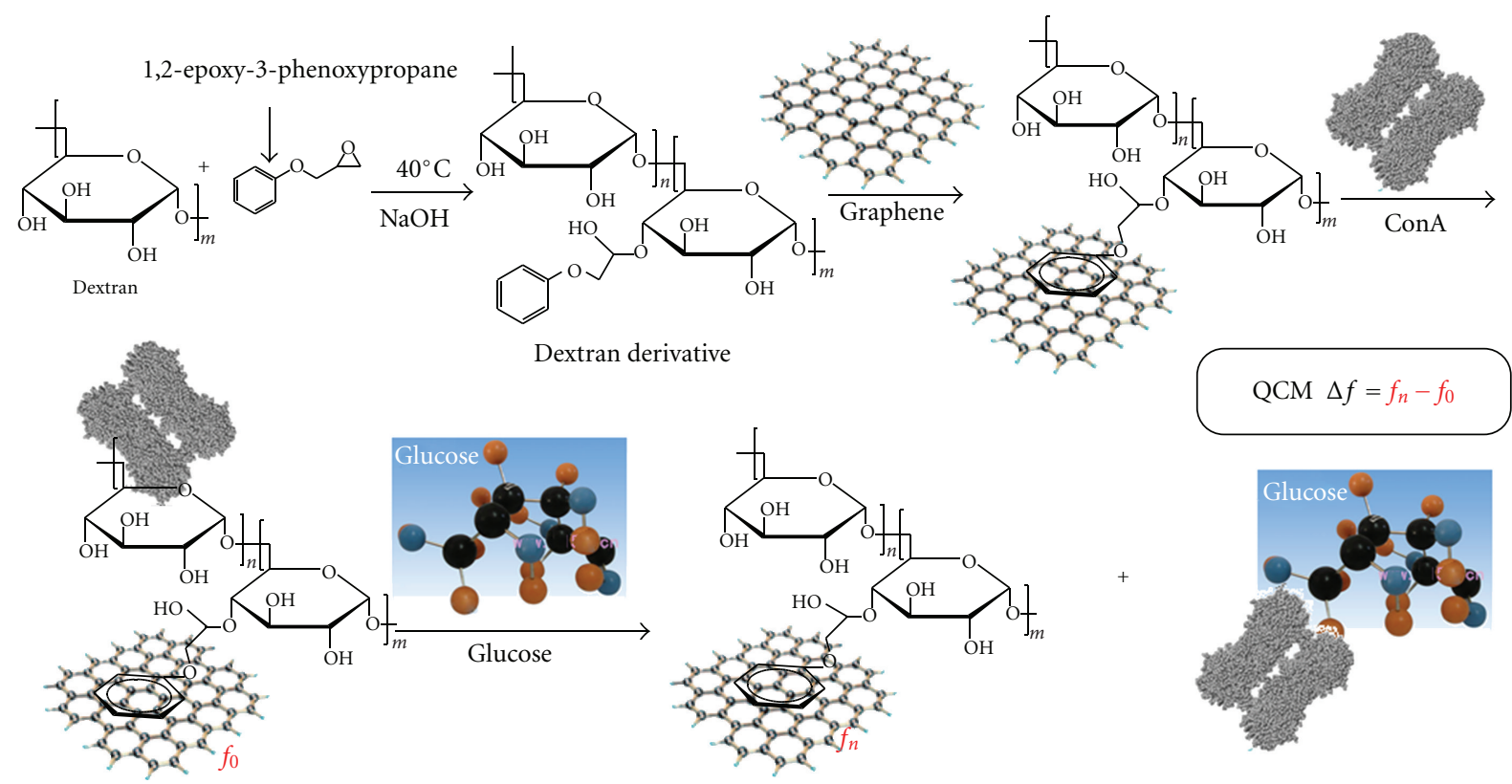

(a)

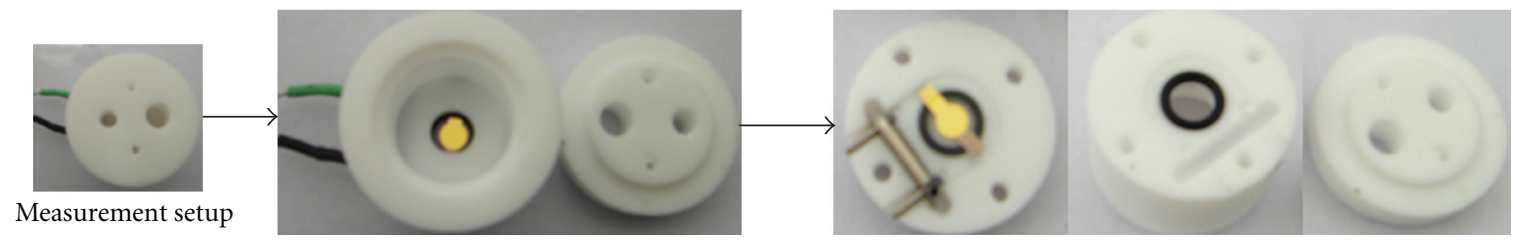

(b)

FIGURE 5: (a) Fabrication process and measurement principle of the displacement-based QCM glucose sensor and (b) the QCM measurement setup (Tang et al., 2011) [36]. (Reprinted with permission from Elsevier B.V.)

different immobilization strategies were employed, where the protein G-based site-specific immobilization strategy was found to be better than the chemical cross-linkingbased strategy as it controlled the orientation and quantity of anti-EGFR-bound to the gold surface. The anti-EGFR coated QCM surface was effectively regenerated four times by treatment with $0.1 \mathrm{M} \mathrm{NaOH}$ for multiple biosensing runs. The dip-and-dry method was found to be more sensitive than the real-time flow cell analysis.

Enantioselective MIP-coated QCM was used for the highly sensitive and selective detection of $\mathrm{L}$ tryptophan with LOD of $8.8 \mu \mathrm{M}$ [41]. MIP was synthesized using acrylamide (AM) as a monomer and trimethylolpropane trimethacrylate (TRIM) as a cross-linking agent. The QCM was then coated with thin permeable film coatings of MIP and the enantioselectivity was demonstrated by the selective detection of L-tryptophan with respect to D-tryptophan in citric acid buffer solutions. The signal obtained by the binding of Ltryptophan was 3-4 fold higher than that obtained from Dtryptophan with the enantiomeric selectivity coefficient of 6.4. The effect of cross-linking agent concentration on the sensitivity and specificity of MIP film was also analysed. MIP, having TRIM/AM molar ratio of 2.21 as the cross-linking monomer concentration, showed the highest sensitivity and enantioselectivity for $\mathrm{L}$ tryptophan out of the four different MIPs synthesized.

QCM with dissipation monitoring (QCM-D) was used for studying the biospecific glycoprotein-lectin interactions, where four lectins were covalently bound to the thiolmodified Au electrodes of QCM [42]. The frequency and dissipation shifts provided information about the analytical concentration and viscoelastic properties of glycoproteinlectin complex, respectively. A unique lectin-binding pattern was displayed for each glycoprotein, which can be used as a fingerprint to discriminate between various glycoproteins. The developed lectin-bound QCM biosensor can detect glycoproteins in linear range of $50 \mu \mathrm{g} / \mathrm{ML}-1 \mathrm{mg} / \mathrm{mL}$ and can be reused many times for two months without any signal loss after regenerating the lectin-bound surface with $10 \mathrm{mM}$ glycine- $\mathrm{HCl}, \mathrm{pH} 2.5$.

QCM was coated with an electropolymerized MIP film of a bis-terthiophene dendron and employed for the detection of folic acid with a linear range of $0-100 \mu \mathrm{M}$ and LOD of $15.4 \mu \mathrm{M}(6.8 \mu \mathrm{g})$ [43] (Figure 7). The relative cross-selectivity 


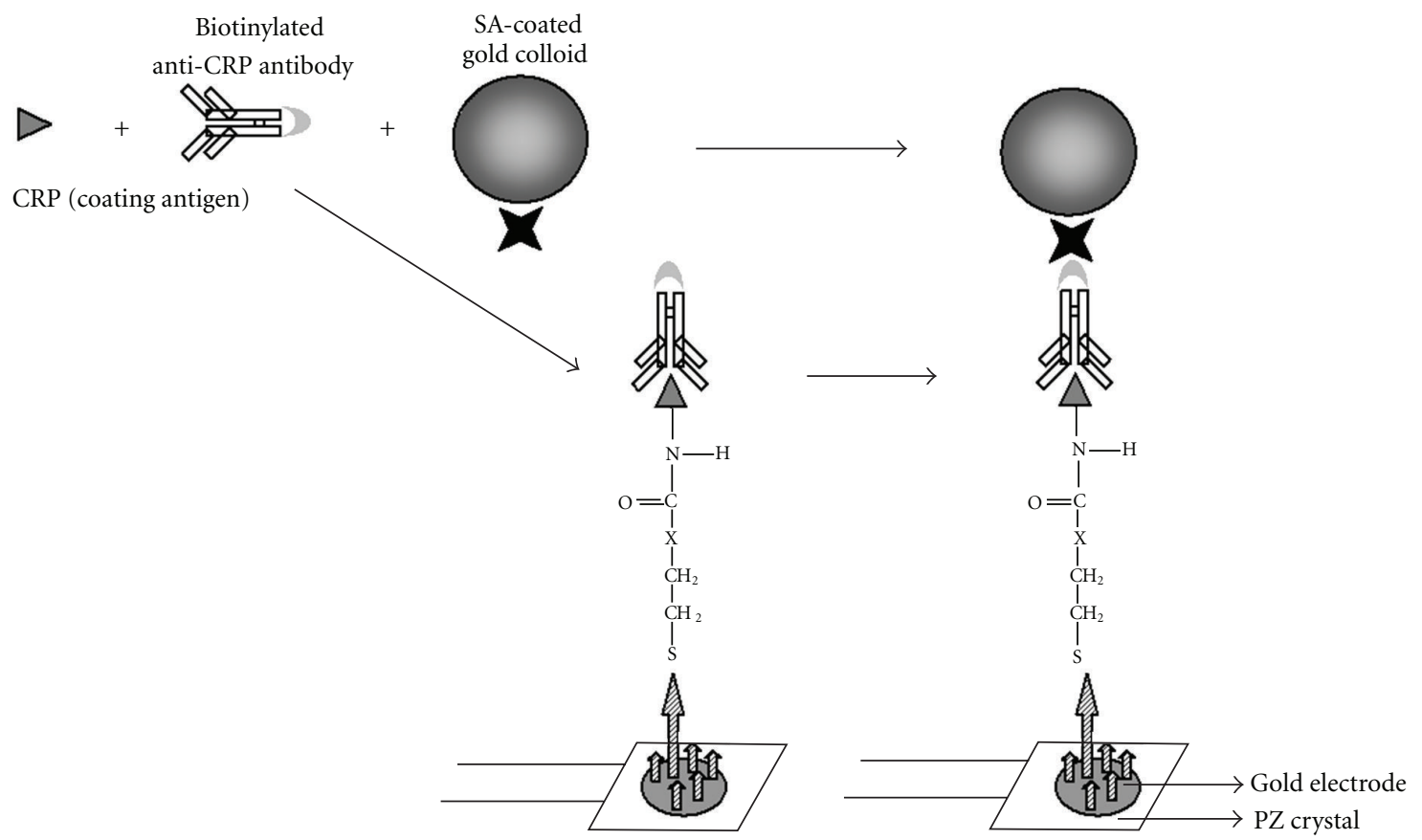

FIGURE 6: Schematic representation of the signal augmentation over QCM surface by the addition of gold colloid in the IC CRP measurement of this study. $\mathrm{X}$ is the residue remaining after antibody immobilization and represents the structure of $-\mathrm{CO}-\mathrm{NH}-\left(\mathrm{CH}_{2}\right)_{5}-(\mathrm{Kim}$ et al., 2010$)$ [39]. (Reprinted with permission from Elsevier B.V.)

of developed QCM sensor for various structurally similar molecules was in the decreasing order of pteroic acid $(50 \%)$ $>$ caffeine $(40 \%)>$ theophylline $(6 \%)$.

\section{Detection of Bacteria}

QCM-based immunosensor was developed for the detection of shrimp pathogenic bacteria, Vibrio harveyi, by the covalent binding of monoclonal antibody against $V$. harveyi onto the Au electrode of $5 \mathrm{MHz}$ QCM [44] (Figure 8). The threestep antibody immobilization procedure was followed, which sequentially involved the formation of SAM of carboxylterminated alkanethiol, that is, 3-mercaptopropionic acid, activation of carboxyl groups by $\mathrm{N}$-hydroxysuccinimide (NHS) and 1-ethyl-3-(3-dimethylaminopropyl) carbodiimide (EDC), and covalent binding of antibody by their amino groups through EDC-NHS heterobifunctional crosslinking. The developed sensor detected $10^{3}-10^{7} \mathrm{CFU} / \mathrm{mL}$ of $V$. harveyi without any cross-reactivity to $V$. vulnificus and $V$. parahaemolyticus. The bacterial binding efficiently was improved by blocking with $1 \%$ bovine serum albumin and by optimizing the monoclonal antibody immobilization density.

QCM-based robust and reproducible procedure was developed for the recognition and discrimination of several Campylobacter jejuni strains by measuring the dissipation shifts of various bacterial strains, when they are bound to the lectins immobilized on the gold-coated QCM surface [45]. The developed procedure would be very useful for the strain discrimination of other bacterial species, especially pathogenic strains that can be bound to lectins.

QCM-based biosensor was developed for the detection of sulphate-reducing bacterium, D. desulfotomaculum with a linear range of $1.8 \times 10^{4}-1.8 \times 10^{7} \mathrm{cfu} / \mathrm{mL}$ [46]. Vancomycin-functionalized magnetic nanoparticles under an external magnetic field formed conjugates with bacteria after $30 \mathrm{~min}$ incubation and got attached to the surface of Au electrode. There was no response to vancomycin-resistant bacterium, Vibrio anguillarum.

\section{Conclusions and Future Trends}

Although QCMs were employed initially in applied physics to study metals in vacuum, it has progressed subsequently to multiple scientific disciplines, such as chemistry, biology, material science, medicine, and environmental monitoring, with increasing complexity of metal interfaces. The QCMbased sensing procedure is simple, cost effective, nonhazardous, real time, and less time, and labour consuming in comparison to conventional assay procedures. Researchers have also demonstrated recently the construction of simultaneous surface-plasmon resonance (SPR) and QCM-sensing platform [49], which would lead to next generation of sensing devices capable of providing lot of useful information for the advancement of analytical sciences. Q-Sense has also developed a new technology called quartz crystal microbalance with dissipation (QCM-D), which enables real-time, label-free measurements of molecular adsorption 

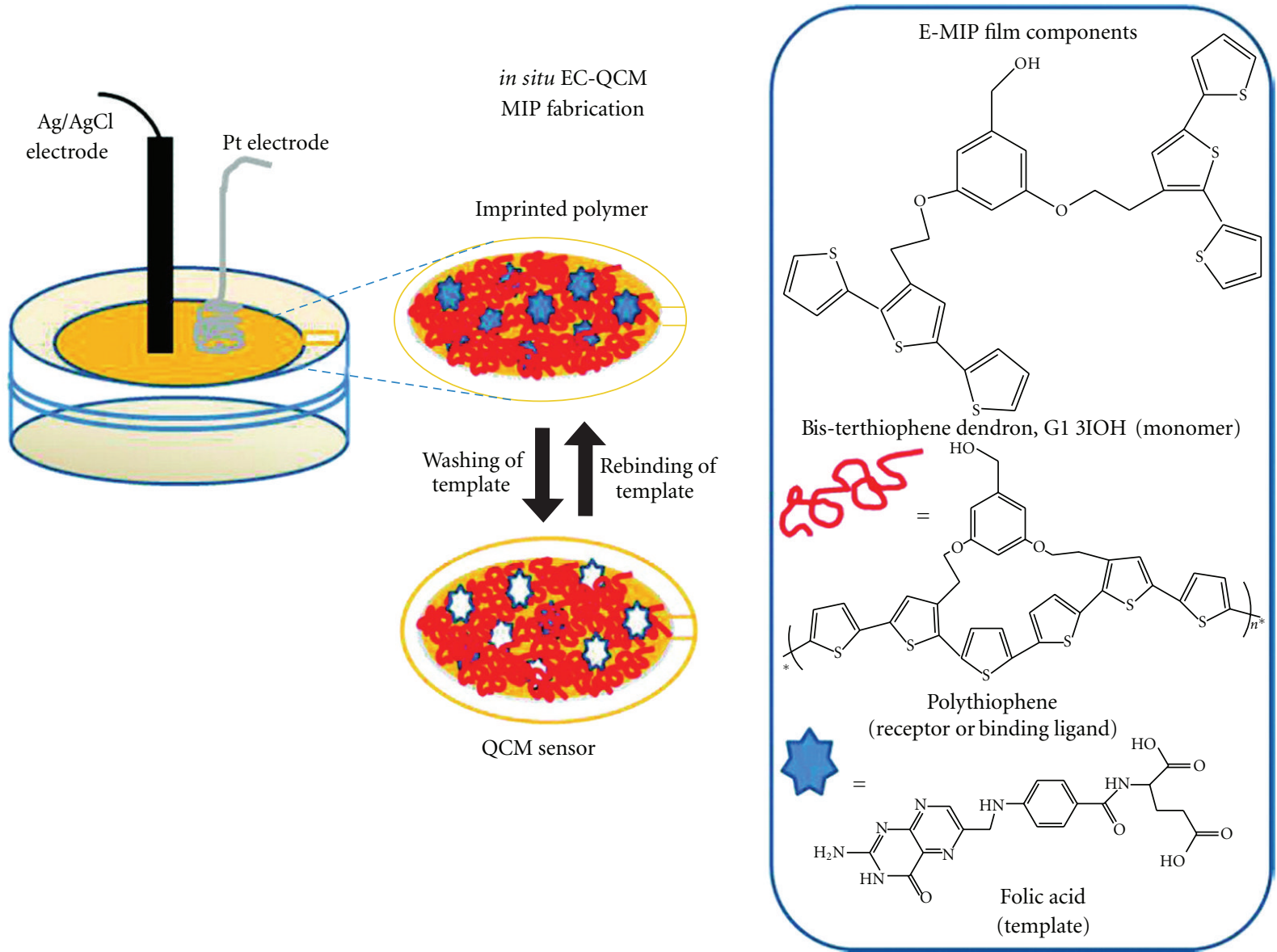

FIGURE 7: Schematic illustration of the fabrication of a polythiophene-based QCM sensor for folic acid (Apodaca et al., 2011) [43]. (Reprinted with permission from ACS Publications.)

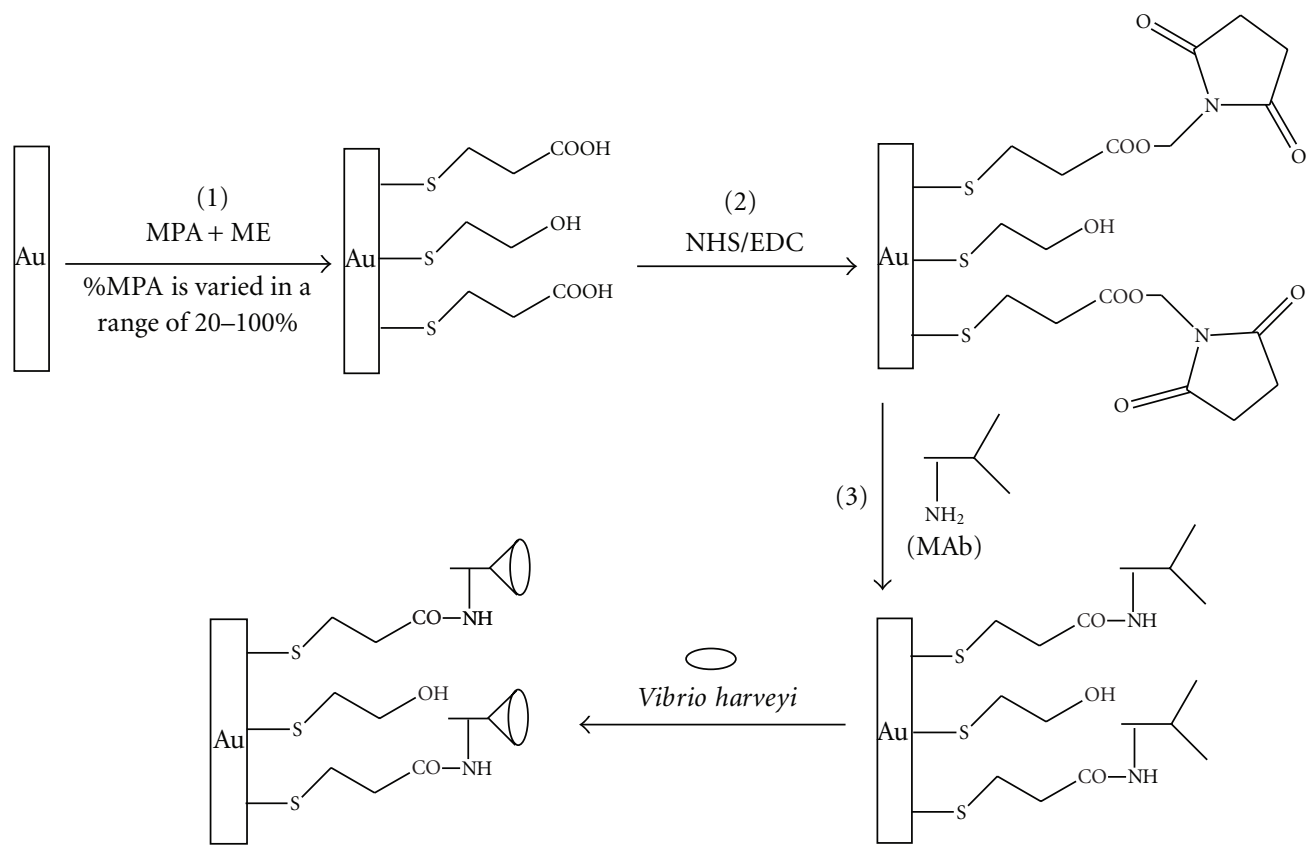

FIGURE 8: Schematic diagram showing the procedure for the preparation of monoclonal antibody-functionalized QCM-based immunosensor for Vibrio harveyi (Buchatip et al., 2010) [44]. (Reprinted with permission from Elsevier B.V.) 
and/or interactions on various surfaces. The dissipation parameter (D) provides novel insights regarding structural (viscoelastic) properties of adsorbed layer. A device based on the simultaneous QCM and electrochemical measurements would also be very useful for providing lot of analytical information. However, electrochemical QCM (EQCM) has a potential limitation as it can only be used for studying electroplated, evaporated, or sputtered materials.

QCM-based sensing concept is mature enough and has been demonstrated for a wide range of analytes, but the robust technology comparison with several commercially available technologies still needs to be critically evaluated to demonstrate its pros and cons with respect to the existing technologies. Presently, there are so many advanced analytical techniques such as SPR-based BIAcore instruments from GE Healthcare, which offer tremendous advantages and are being used on a very large scale in industries, academia, and healthcare. In addition, there are microtiter plate immunoassays such as enzyme-linked immunosorbent assays, fluorescent immunoassays, and chemiluminescent immunoassays, which have very high sensitivity and high throughput and are still used widely as the gold standard for disease diagnostics. However, QCM may find a particular niche in certain sensing applications based on the technology advancement in the near future. It has already been demonstrated recently that the development of a combined system, such as QCM and SPR or QCM and electrochemical measurement system, would be immensely useful as it would provide lot of additionally useful information in comparison to an individual analytical technique.

\section{References}

[1] J. Curie and P. Curie, "An oscillating quartz crystal mass detector," Rendu, vol. 91, pp. 294-297, 1880.

[2] G. Z. Sauerbrey, "Use of quartz vibration for weighing thin films on a microbalance," Physik Journal, vol. 155, pp. 206212, 1959.

[3] H. H. Lu, Y. K. Rao, T. Z. Wu, and Y. M. Tzeng, "Direct characterization and quantification of volatile organic compounds by piezoelectric module chips sensor," Sensors and Actuators B, vol. 137, no. 2, pp. 741-746, 2009.

[4] M. M. Ayad and N. L. Torad, "Alcohol vapours sensor based on thin polyaniline salt film and quartz crystal microbalance," Talanta, vol. 78, no. 4-5, pp. 1280-1285, 2009.

[5] A. Bello, F. Bianchi, M. Careri et al., "Potentialities of a modified QCM sensor for the detection of analytes interacting via $\mathrm{H}$-bonding and application to the determination of ethanol in bread," Sensors and Actuators B, vol. 125, no. 1, pp. 321-325, 2007.

[6] M. Kikuchi and S. Shiratori, "Quartz crystal microbalance (QCM) sensor for $\mathrm{CH}_{3} \mathrm{SH}$ gas by using polyelectrolyte-coated sol-gel film," Sensors and Actuators B, vol. 108, no. 1-2, pp. 564-571, 2005.

[7] Z. Ying, Y. Jiang, X. Du, G. Xie, J. Yu, and H. Tai, "Polymer coated sensor array based on quartz crystal microbalance for chemical agent analysis," European Polymer Journal, vol. 44, no. 4, pp. 1157-1164, 2008.

[8] Z. Ying, Y. Jiang, X. Du, G. Xie, J. Yu, and H. Wang, "PVDF coated quartz crystal microbalance sensor for DMMP vapor detection," Sensors and Actuators B, vol. 125, no. 1, pp. 167$172,2007$.

[9] I. A. Koshets, Z. I. Kazantseva, Y. M. Shirshov, S. A. Cherenok, and V. I. Kalchenko, "Calixarene films as sensitive coatings for QCM-based gas sensors," Sensors and Actuators B, vol. 106, no. 1, pp. 177-181, 2005.

[10] M. Matsuguchi and T. Uno, "Molecular imprinting strategy for solvent molecules and its application for QCM-based VOC vapor sensing," Sensors and Actuators B, vol. 113, no. 1, pp. 9499, 2006.

[11] J. Rabe, S. Büttgenbach, J. Schröder, and P. Hauptmann, "Monolithic miniaturized quartz microbalance array and its application to chemical sensor systems for liquids," IEEE Sensors Journal, vol. 3, no. 4, pp. 361-368, 2003.

[12] F. L. Dickert, O. Hayden, and M. E. Zenkel, "Detection of volatile compounds with mass-sensitive sensor arrays in the presence of variable ambient humidity," Analytical Chemistry, vol. 71, no. 7, pp. 1338-1341, 1999.

[13] B. Wyszynski, P. Somboon, and T. Nakamoto, "Chemisorbed PEGylated lipopolymers as sensing film supports for QCM odor sensors," Sensors and Actuators B, vol. 130, no. 2, pp. 857863, 2008.

[14] J. W. Park, S. Kurosawa, H. Aizawa, Y. Goda, M. Takai, and K. Ishihara, "Piezoelectric immunosensor for bisphenol A based on signal enhancing step with 2-methacrolyloxyethyl phosphorylcholine polymeric nanoparticle," Analyst, vol. 131, no. 1, pp. 155-162, 2006.

[15] J. W. Park, S. Kurosawa, H. Aizawa et al., "Dioxin immunosensor using anti-2,3,7,8-TCDD antibody which was produced with mono 6-(2,3,6,7-tetrachloroxanthene-9-ylidene) hexyl succinate as a hapten," Biosensors and Bioelectronics, vol. 22, no. 3, pp. 409-414, 2006.

[16] H. Zeng, Y. Jiang, G. Xie, and J. Yu, "Polymer coated QCM sensor with modified electrode for the detection of DDVP," Sensors and Actuators B, vol. 122, no. 1, pp. 1-6, 2007.

[17] Y. K. Yuan, X. L. Xiao, Y. S. Wang et al., "Quartz crystal microbalance with $\beta$-cyclodextrin $/ \mathrm{TiO}_{2}$ composite films coupled with chemometrics for the simultaneous determination of urinary 1- and 2-naphthol," Sensors and Actuators B, vol. 145, no. 1, pp. 348-354, 2010.

[18] M. Matsuguchi, Y. Kadowaki, K. Noda, and R. Naganawa, " $\mathrm{HCl}$ gas monitoring based on a QCM using morpholinefunctional styrene-co-chloromethylstyrene copolymer coatings," Sensors and Actuators B, vol. 120, no. 2, pp. 462-466, 2007.

[19] M. Matsuguchi and Y. Kadowaki, "Poly(acrylamide) derivatives for QCM-based $\mathrm{HCl}$ gas sensor applications," Sensors and Actuators B, vol. 130, no. 2, pp. 842-847, 2008.

[20] P. Sun, Y. Jiang, G. Xie, X. Du, and J. Hu, “A room temperature supramolecular-based quartz crystal microbalance (QCM) methane gas sensor," Sensors and Actuators B, vol. 141, no. 1, pp. 104-108, 2009.

[21] G. Xie, P. Sun, X. Yan, X. Du, and Y. Jiang, "Fabrication of methane gas sensor by layer-by-layer self-assembly of polyaniline/PdO ultra thin films on quartz crystal microbalance," Sensors and Actuators B, vol. 145, no. 1, pp. 373-377, 2010.

[22] A. Palaniappan, S. Moochhala, F. E. H. Tay, X. Su, and N. C. L. Phua, "Phthalocyanine/silica hybrid films on QCM for enhanced nitric oxide sensing," Sensors and Actuators B, vol. 129, no. 1, pp. 184-187, 2008 .

[23] M. Matsuguchi, Y. Kadowaki, and M. Tanaka, "A QCM-based $\mathrm{NO}_{2}$ gas detector using morpholine-functional cross-linked copolymer coatings," Sensors and Actuators B, vol. 108, no. 1-2, pp. $572-575,2005$. 
[24] F. L. Dickert, A. Haunschild, V. Kuschow, M. Reif, and H. Stathopulos, "Mass-sensitive detection of solvent vapors. Mechanistic studies on host-guest sensor principles by FTIR spectroscopy and BET adsorption analysis," Analytical Chemistry, vol. 68, no. 6, pp. 1058-1061, 1996.

[25] B. Ding, J. Kim, Y. Miyazaki, and S. Shiratori, "Electrospun nanofibrous membranes coated quartz crystal microbalance as gas sensor for $\mathrm{NH}_{3}$ detection," Sensors and Actuators B, vol. 101, no. 3, pp. 373-380, 2004.

[26] N. Van Quy, V. A. Minh, N. Van Luan, V. N. Hung, and N. Van Hieu, "Gas sensing properties at room temperature of a quartz crystal microbalance coated with $\mathrm{ZnO}$ nanorods," Sensors and Actuators B, vol. 153, pp. 188-93, 2011.

[27] S. W. Lee, N. Takahara, S. Korposh, D. H. Yang, K. Toko, and T. Kunltake, "Nanoassembled thin film gas sensors. III. sensitive detection of amine odors using $\mathrm{TiO}_{2} /$ poly(acrylic acid) ultrathin film quartz crystal microbalance sensors," Analytical Chemistry, vol. 82, no. 6, pp. 2228-2236, 2010.

[28] C. Zhang, X. Wang, J. Lin, B. Ding, J. Yu, and N. Pan, "Nanoporous polystyrene fibers functionalized by polyethyleneimine for enhanced formaldehyde sensing," Sensors and Actuators B, vol. 152, pp. 316-323, 2011.

[29] H. S. Guo, J. M. Kim, S. M. Chang, and W. S. Kim, "Chiral recognition of mandelic acid by 1-phenylalanine-modified sensor using quartz crystal microbalance," Biosensors and Bioelectronics, vol. 24, no. 9, pp. 2931-2934, 2009.

[30] S. Muñoz-Aguirre, A. Yoshino, T. Nakamoto, and T. Moriizumi, "Odor approximation of fruit flavors using a QCM odor sensing system," Sensors and Actuators B, vol. 123, no. 2, pp. 1101-1106, 2007.

[31] A. Ozmen, F. Fekce, M. A. Ebeoglu, C. Tasaltin, and Z. Z. Ozturk, "Finding the composition of gas mixtures by a phthalocyanine-coated QCM sensor array and an artificial neural network," Sensors and Actuators B, vol. 115, pp. 450454, 2006.

[32] Y. Zhu, H. Yuan, J. Xu, P. Xu, and Q. Pan, "Highly stable and sensitive humidity sensors based on quartz crystal microbalance coated with hexagonal lamelliform monodisperse mesoporous silica SBA-15 thin film," Sensors and Actuators B, vol. 144, no. 1, pp. 164-169, 2010.

[33] M. M. Ayad, N. Prastomo, A. Matsuda, and J. Stejskal, "Sensing of silver ions by nanotubular polyaniline film deposited on quartz-crystal in a microbalance," Synthetic Metals, vol. 160, no. 1-2, pp. 42-46, 2010.

[34] M. E. Escuderos, S. Sánchez, and A. Jiménez, “Quartz Crystal Microbalance (QCM) sensor arrays selection for olive oil sensory evaluation," Food Chemistry, vol. 124, no. 3, pp. 857862, 2011.

[35] V. Reipa, G. Purdum, and J. Choi, "Measurement of nanoparticle concentration using quartz crystal microgravimetry," Journal of Physical Chemistry B, vol. 114, no. 49, pp. 16112 16117, 2010.

[36] D. Tang, Q. Li, J. Tang, B. Su, and G. Chen, "An enzymefree quartz crystal microbalance biosensor for sensitive glucose detection in biological fluids based on glucose/dextran displacement approach," Analytica Chimica Acta, vol. 686, pp. 144-149, 2011.

[37] T. Y. Lin, C. H. Hu, and T. C. Chou, "Determination of albumin concentration by MIP-QCM sensor," Biosensors and Bioelectronics, vol. 20, no. 1, pp. 75-81, 2004.

[38] Y. Uludağ and I. E. Tothill, "Development of a sensitive detection method of cancer biomarkers in human serum (75\%) using a quartz crystal microbalance sensor and nanoparticles amplification system," Talanta, vol. 82, no. 1, pp. 277-282, 2010.

[39] N. Kim, D. K. Kim, and Y. J. Cho, "Gold nanoparticlebased signal augmentation of quartz crystal microbalance immunosensor measuring C-reactive protein," Current Applied Physics, vol. 10, no. 4, pp. 1227-1230, 2010.

[40] J. C. Chen, S. Sadhasivam, and F. H. Lin, "Label free gravimetric detection of epidermal growth factor receptor by antibody immobilization on quartz crystal microbalance," Process Biochemistry, vol. 46, no. 2, pp. 543-550, 2011.

[41] F. Liu, X. Liu, S. C. Ng, and H. S. O. Chan, "Enantioselective molecular imprinting polymer coated QCM for the recognition of l-tryptophan," Sensors and Actuators B, vol. 113, no. 1, pp. 234-240, 2006.

[42] M. E. Yakovleva, G. R. Safina, and B. Danielsson, "A study of glycoprotein-lectin interactions using quartz crystal microbalance," Analytica Chimica Acta, vol. 668, no. 1, pp. 80-85, 2010.

[43] D. C. Apodaca, R. B. Pernites, R. R. Ponnapati, F. R. Del Mundo, and R. C. Advincula, "Electropolymerized molecularly imprinted polymer films of a bis-terthiophene dendron: folic acid quartz crystal microbalance sensing," ACS Applied Materials \& Interfaces, vol. 3, pp. 191-203, 2011.

[44] S. Buchatip, C. Ananthanawat, P. Sithigorngul, P. Sangvanich, S. Rengpipat, and V. P. Hoven, "Detection of the shrimp pathogenic bacteria, Vibrio harveyi, by a quartz crystal microbalance-specific antibody based sensor," Sensors and Actuators B, vol. 145, no. 1, pp. 259-264, 2010.

[45] M. E. Yakovleva, A. P. Moran, G. R. Safina, T. Wadstrom, and B. Danielsson, "Lectin typing of Campylobacter jejuni using a novel quartz crystal microbalance technique," Analytica Chimica Acta, vol. 694, no. 1-2, pp. 1-5, 2011.

[46] Y. Wan, D. Zhang, and B. Hou, "Determination of sulphatereducing bacteria based on vancomycin-functionalized magnetic nanoparticles using a modification-free quartz crystal microbalance," Biosensors \& Bioelectronics, vol. 25, no. 7, pp. 1847-1850, 2010.

[47] N. Tsuru, M. Kikuchi, H. Kawaguchi, and S. Shiratori, "A quartz crystal microbalance sensor coated with MIP for "Bisphenol A" and its properties," Thin Solid Films, vol. 499, no. 1-2, pp. 380-385, 2006.

[48] S. Kurosawa, H. Aizawa, and J. W. Park, "Quartz crystal microbalance immunosensor for highly sensitive 2,3,7,8tetrachlorodibenzo- $p$-dioxin detection in fly ash from municipal solid waste incinerators," Analyst, vol. 130, no. 11, pp. 1495-1501, 2005.

[49] J. Kim, S. Kim, T. Ohashi, H. Muramatsu, S. M. Chang, and W. S. Kim, "Construction of simultaneous SPR and QCM sensing platform," Bioprocess and Biosystems Engineering, vol. 33, no. 1, pp. 39-45, 2010. 

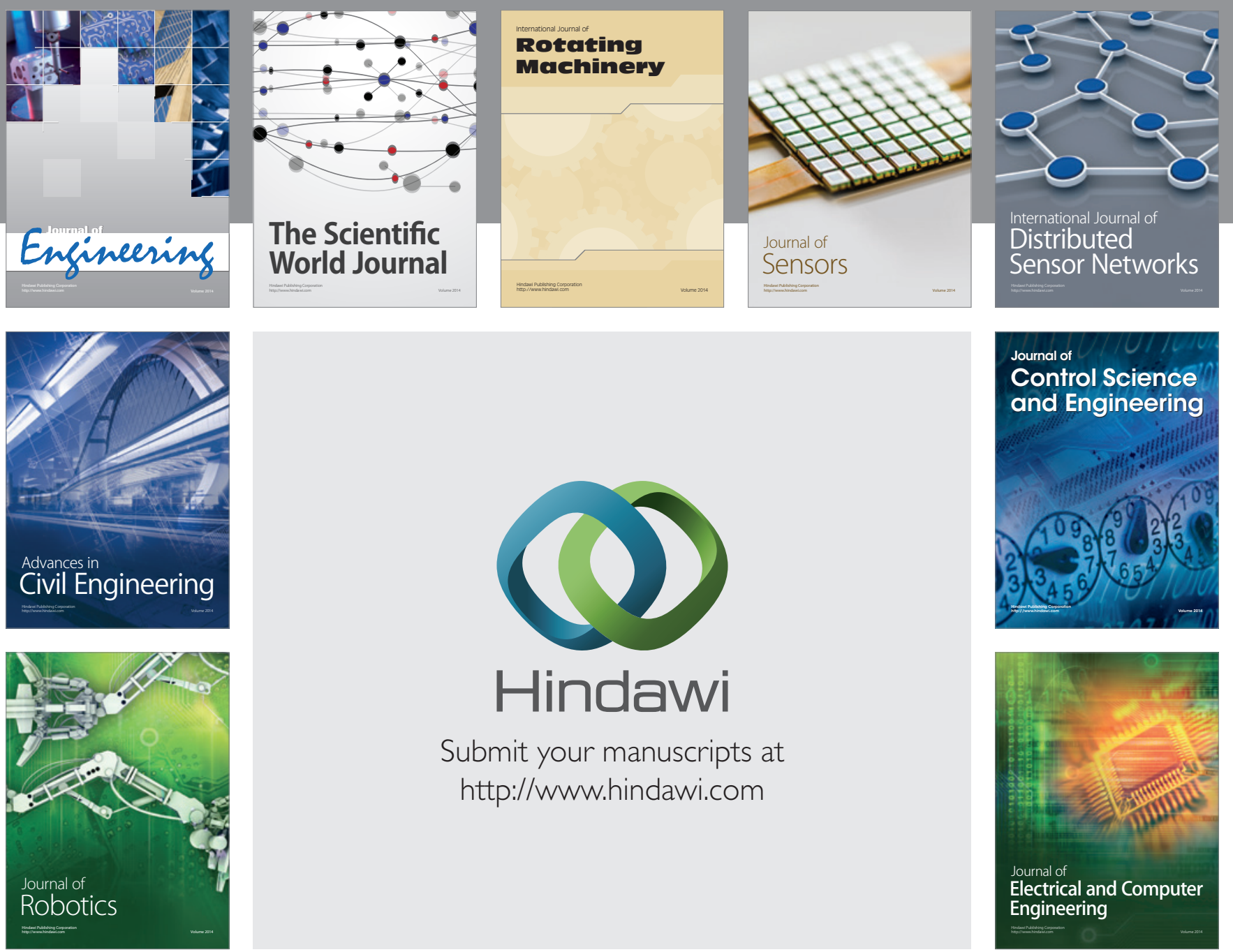

Submit your manuscripts at

http://www.hindawi.com
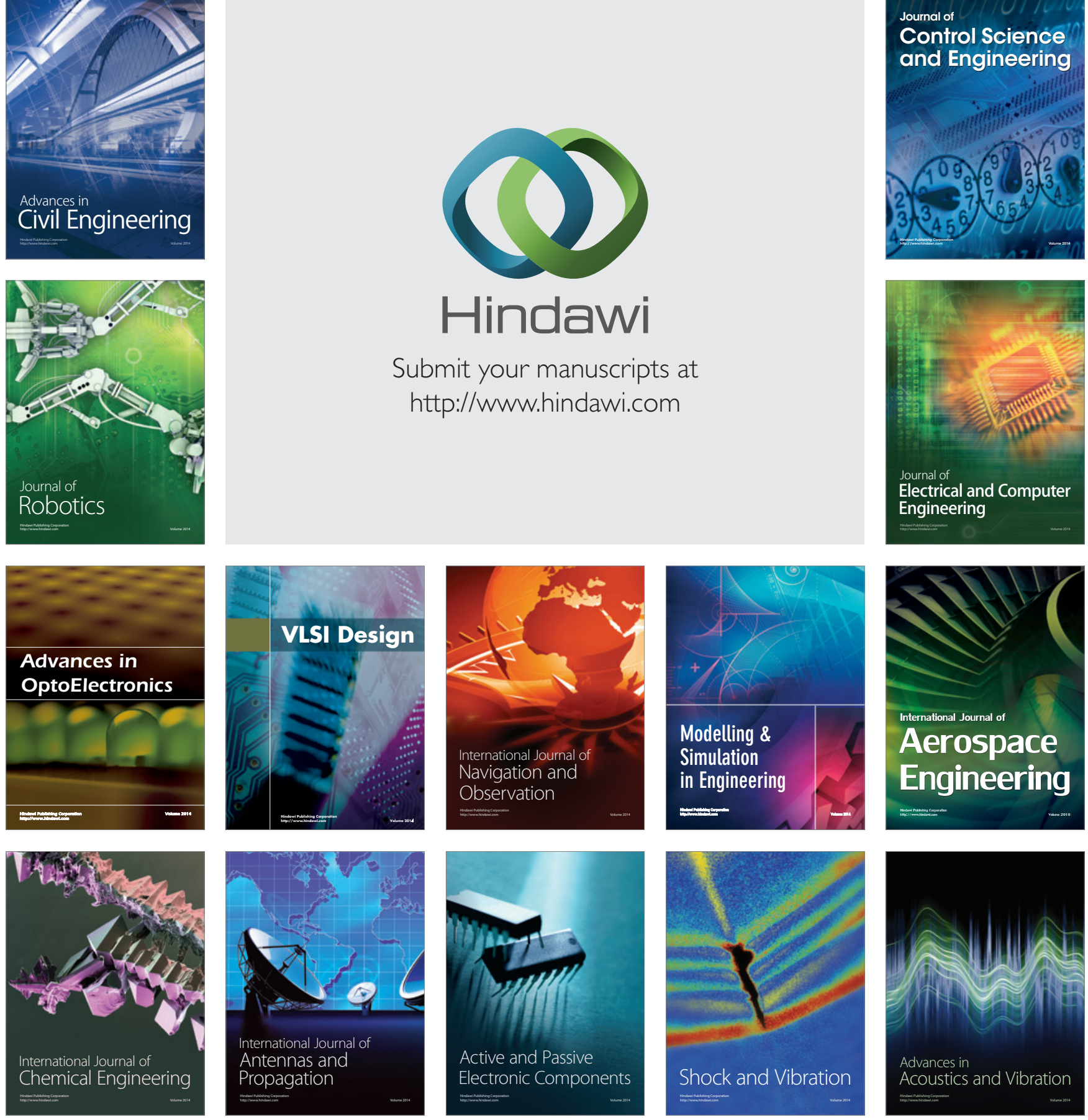